\title{
Inovação e pesquisa no setor automotivo de Pernambuco: o caso do Centro de Pesquisa, Desenvolvimento, Inovação e Engenharia da FCA (FIAT-Chrysler Automobile)
}

\author{
João Policarpo R. Lima ${ }^{1}$ \\ Abraham B. Sicsú ${ }^{2}$
}

\begin{abstract}
Resumo: A recente inauguração da fábrica de automóveis da FIAT-CHRYSLER AUTOMOBILE - FCA, no município de Goiana, abre enormes perspectivas de ampliação do setor industrial de Pernambuco para além da região situada no entorno mais próximo do distrito industrial portuário de Suape, bem como permite antever a possibilidade do estabelecimento de uma maior articulação do segmento automobilístico com outros segmentos e empresas préexistentes e a serem atraídos para integração com o segmento motriz. Ao lado do segmento automobilístico de óbvia importância, já existe no território uma base significativa de pesquisadores e instituições de suporte tecnológico, além de um segmento de TI formado por um bom número de empresas aglomeradas no Porto Digital, no Recife, mas também em outros municípios, como é o caso de Olinda. Essa conjunção de uma base razoavelmente significativa de C, T\&I já disponível no território com a instalação de uma montadora com tecnologia de ponta do ponto de vista mundial gerou expectativas de formação no Estado de Pernambuco de um polo dinâmico de desenvolvimento tecnológico, abrangendo as competências já existentes com a interação com a FCA e um Centro de Desenvolvimento Tecnológico que se pretendia de Classe Mundial. Tal Centro, imaginava-se, seria um diferencial para um Estado do Nordeste subdesenvolvido num país ainda em vias de desenvolvimento. Essa expectativa otimista está sendo arrefecida pela crise da economia brasileira e mundial, além de mudanças no próprio quadro político e econômico do Estado, o que, no mínimo, poderá adiar a constituição plena do Centro referido e de seus efeitos dinâmicos. Cabe ressaltar que essa é uma estratégia de longo prazo, mas que, em tempos de crise, ocorrem retrocessos e pode haver uma tendência de concentração da pesquisa estratégica nos centros já consolidados. 0 que parece é que, com a ocorrência de crises, as economias periféricas, portanto mais frágeis, tornam-se menos atrativas para investimentos de maior risco. Reconhece-se a importância que o Centro vem tendo para o Estado e os impactos significativos em sua economia, mas, chama-se a atenção
\end{abstract}

1 João Policarpo R. Lima (jprlima@ufpe.br), Ph. D. em Economia pela Universidade de Londres; Professor Titular do Departamento de Economia/PIMES da UFPE e pesquisador do CNPq.

2 Abraham B. Sicsú (asicsu@globo.com), Doutor em Economia pela UNICAMP; Pesquisador Titular, aposentado, da Fundação Joaquim Nabuco e Professor Aposentado do Departamento de Engenharia de Produção da UFPE. 
para mudanças significativas que o projeto inicial vem sofrendo. Este trabalho objetiva avaliar a viabilidade da instalação do Centro de acordo com o previsto, encontrar possíveis explicações para a já detectada mudança de planos e mostrar as dificuldades e fragilidades de economias em desenvolvimento no sentido de avançar no quesito capacitação tecnológica e de vir a ter uma dinâmica tecnológica autônoma, a exemplo de alguns outros países fora do chamado "Centro" desenvolvido, que já superaram essas dificuldades.

Palavras-chave: Centros Tecnológicos. Desenvolvimento tecnológico. Indústria automobilística.

Classificação JEL: 032, 033.

\title{
Innovation and research in Pernambuco's automotive sector: the case of the FCA (FIAT-Chrysler Automobile) Development, Innovation and Engineering Research Centre.
}

\begin{abstract}
The recent opening of the car factory of FIAT-CHRYSLER AUTOMOBILE FCA, in the municipality of Goiana, opens up tremendous prospects for the expansion of the industrial sector of Pernambuco, as well as allows you foresee the possibility of the establishment of a greater articulation of the car industry with other industries and companies pre-existing and others to be attracted and integrated themselves with the FCA plant. Besides the car industry, of obvious importance, there is in the territory a meaningful basis of researchers and institutions of technological support, in addition to a segment of IT formed by a good number of firms agglomerated in the Porto Digital, in Recife, but also in other municipalities as is the case of Olinda. This conjunction of a C,T\&I basis reasonably significant is already available in the territory with the installation of an automaker with cutting edge technology has generated expectations of stablishing in the State of Pernambuco a dynamic focus of technological development encompassing the existing skills with interaction with the FCA and a Technological Development Center intended to be a world class one. Such a Centre would be a differential for a State in the Northeast undeveloped in a country still in its process of development. This optimist expectation is being cooled by the economic crisis (Brazil and the world), besides changes in the state political and economic scenario, which, at a minimum, may be able to postpone the full constitution of the Center referred to and of their dynamic effects. It seems that with the occurrence of crises, the countries in the peripheral economies, therefore more fragile, become less attractive for higher risky investments. This paper aims at analyzing the viability of such a Centre, finding possible explanations for the already detected change of plans on the Centre and shows the difficulties and weaknesses of the developing economies in the sense of moving forward in terms of technological capacity and come to have more technological dynamism.
\end{abstract}

Keywords: Technological Centers. Technological development. Automobile industry. 


\section{Introdução}

A recente inauguração da fábrica de automóveis da FIAT-CHRYSLER AUTOMOBILE - FCA, no município de Goiana, abre enormes perspectivas de ampliação do setor industrial de Pernambuco para além da região situada no entorno mais próximo do distrito industrial portuário de Suape, bem como permite antever a possibilidade do estabelecimento de uma maior articulação do segmento automobilístico com outros segmentos e empresas preexistentes e a serem atraídos para integração com o segmento motriz.

Devido ao que já existe em termos de empresas do setor de TI junto com a FCA e suas empresas sistemistas, esse trabalho definiu o território onde se concentram essas atividades e onde tendem a se instalar novos empreendimentos. Tal território é formado por 11 municípios, incluindo Goiana, sede da FCA, Belo Jardim, onde fica a fábrica da Baterias Moura e Glória do Goitá por ter uma empresa de fundições e a WHB, que se integra ao segmento automobilístico. Os demais municípios (Abreu e Lima, Cabo de Santo Agostinho, Igarassu, Itapissuma, Jaboatão dos Guararapes, Olinda e Recife) constituem um subconjunto da Região Metropolitana do Recife. Estes últimos desenvolvem atividades ligadas ao setor de TI e/ou automobilístico. No conjunto dos 11 municípios foram registrados pela base de dados da RAIS, em 2014, 3.878 estabelecimentos e 47.278 vínculos empregatícios nos setores de Tecnologia da Informação e/ou Automobilístico. Nesse espaço, localizam-se 51,8 \% dos estabelecimentos do Estado de Pernambuco e 69,7 \% dos vínculos de emprego nos setores em questão (Quadro 1).

Ao lado do segmento automobilístico de óbvia importância, já existe no território uma base significativa de pesquisadores e instituições de suporte tecnológico, além de um segmento de TI formado por um bom número de empresas aglomeradas no Porto Digital, no Recife, mas também em outros municípios, como é o caso de Olinda.

Essa conjunção de uma base razoavelmente significativa de C, T\&I já disponível no território com a instalação de uma montadora com tecnologia de ponta do ponto de vista mundial gerou expectativas de formação no Estado de Pernambuco de um polo dinâmico de desenvolvimento tecnológico, abrangendo as competências já existentes com a interação com a FCA e um Centro de Desenvolvimento Tecnológico. Este foi articulado por instituições do Governo Estadual e pelas demais entidades juntamente com a montadora, já mesmo na fase de instalação desta e imaginava-se que seria um diferencial para um Estado do Nordeste subdesenvolvido num país ainda em vias de desenvolvimento. Portanto, um fato novo e auspicioso capaz de gerar desdobramentos importantes sobre a base produtiva e sobre a dinâmica tecnológica do Estado e do País. 
Quadro 1: Pernambuco e municípios selecionados - Composição, estabelecimentos e vínculos ativos nos setores de Tecnologia da Informação e Automobilístico e empreendimentos de destaque no Setor Automobilístico, 2015

\begin{tabular}{|c|c|c|c|c|c|c|c|}
\hline \multirow{2}{*}{$\begin{array}{l}\text { Empreendimentos } \\
\text { de destaque }\end{array}$} & \multirow{2}{*}{$\begin{array}{l}\text { Unidade } \\
\text { espacial }\end{array}$} & \multicolumn{3}{|c|}{ Estabelecimentos } & \multicolumn{3}{|c|}{ Vínculos } \\
\hline & & No & \multicolumn{2}{|l|}{$(\%)$} & No & \multicolumn{2}{|l|}{$(\%)$} \\
\hline & $\begin{array}{c}\text { Pernambuco } \\
(\mathrm{PE})\end{array}$ & 7.492 & \multicolumn{2}{|l|}{100} & 67.848 & \multicolumn{2}{|l|}{100} \\
\hline & $\begin{array}{c}\text { Municípios } \\
\text { (TI- } \\
\text { Automotivo) }\end{array}$ & 3.878 & $\mathrm{TI} / \mathrm{PE}$ & 51,8 & 47.278 & $\mathrm{TI} / \mathrm{PE}$ & 69,7 \\
\hline & Abreu e Lima & 77 & $\begin{array}{c}\text { Município/ } \\
\text { TI }\end{array}$ & 2,0 & 348 & $\begin{array}{c}\text { Município/ } \\
\text { TI }\end{array}$ & 0,7 \\
\hline \multirow[t]{3}{*}{ Baterias Moura } & Belo Jardim & 65 & $\begin{array}{c}\text { Município/ } \\
\text { TI }\end{array}$ & 1,7 & 1.762 & $\begin{array}{c}\text { Município/ } \\
\text { TI }\end{array}$ & 3,7 \\
\hline & $\begin{array}{c}\text { Cabo de Santo } \\
\text { Agostinho }\end{array}$ & 123 & $\begin{array}{c}\text { Município/ } \\
\text { TI }\end{array}$ & 3,2 & 1.561 & $\begin{array}{c}\text { Município/ } \\
\text { TI }\end{array}$ & 3,3 \\
\hline & Camaragibe & 61 & $\begin{array}{l}\text { Município/ } \\
\text { TI }\end{array}$ & 1,6 & 263 & $\begin{array}{l}\text { Município/ } \\
\text { TI }\end{array}$ & 0,6 \\
\hline WHB Fundição & $\begin{array}{l}\text { Glória do } \\
\text { Goitá }\end{array}$ & 6 & $\begin{array}{c}\text { Município/ } \\
\text { TI }\end{array}$ & 0,2 & 31 & $\begin{array}{c}\text { Município/ } \\
\text { TI }\end{array}$ & 0,1 \\
\hline JEEP & Goiana & 68 & $\begin{array}{c}\text { Município/ } \\
\text { TI }\end{array}$ & 1,8 & 396 & $\begin{array}{c}\text { Município/ } \\
\text { TI }\end{array}$ & 0,8 \\
\hline Segunda geração & Igarassu & 70 & $\begin{array}{l}\text { Município/ } \\
\text { TI }\end{array}$ & 1,8 & 1.227 & $\begin{array}{l}\text { Município/ } \\
\text { TI }\end{array}$ & 2,6 \\
\hline $\begin{array}{l}\text { de rornecedores } \\
\text { da FCA }\end{array}$ & Itapissuma & 3 & $\begin{array}{c}\text { Município/ } \\
\text { TI }\end{array}$ & 0,1 & 5 & $\begin{array}{c}\text { Município/ } \\
\text { TI }\end{array}$ & 0,0 \\
\hline \multirow[t]{2}{*}{ TCA } & $\begin{array}{l}\text { Jaboatão dos } \\
\text { Guararapes }\end{array}$ & 448 & $\begin{array}{c}\text { Município/ } \\
\text { TI }\end{array}$ & 11,6 & 7.301 & $\begin{array}{c}\text { Município/ } \\
\text { TI }\end{array}$ & 15,4 \\
\hline & Olinda & 358 & $\begin{array}{c}\text { Município/ } \\
\text { TI }\end{array}$ & 9,2 & 2.833 & $\begin{array}{c}\text { Município/ } \\
\text { TI }\end{array}$ & 6,0 \\
\hline $\begin{array}{c}\text { P\&D da FCA; } \\
\text { CH\&TCR }\end{array}$ & Recife & 2.599 & $\begin{array}{c}\text { Município/ } \\
\text { TI } \\
\end{array}$ & 67,0 & 31.551 & $\begin{array}{c}\text { Município/ } \\
\text { TI } \\
\end{array}$ & 66,7 \\
\hline
\end{tabular}

Fonte: Ministério do Trabalho e Emprego/ RAIS (2014).

Essas perspectivas otimistas estão sendo arrefecidas pelo andar da crise da economia mundial, particularmente da economia brasileira, o que, no mínimo, poderá 
adiar a constituição plena do Centro referido e de seus efeitos dinâmicos. 0 que parece é que, com a ocorrência de crises, as economias periféricas, portanto mais frágeis em geral e especificamente do ponto de vista do dinamismo tecnológico, tornam-se menos atrativas para investimentos de maior risco, como é o caso dos centros de desenvolvimento tecnológico. Nesse caso, a preferência das montadoras volta-se para concentrar atenções estratégicas nas fábricas já consolidadas, principalmente as localizadas nas respectivas matrizes.

Para entender melhor essa problemática e os desafios enfrentados por regiões menos desenvolvidas no tocante à dinâmica tecnológica nesse setor, este trabalho contém esta introdução; a seção seguinte trata do ponto de vista teórico sobre inovação, dinâmica tecnológica e desenvolvimento econômico; numa seção seguinte, apresenta-se o contexto geral do território mais diretamente afetado pela vinda da montadora da FCA; uma outra mostra a base de C, T\&I sediada nesse território; outra seção discute as políticas públicas que apoiaram a vinda da montadora para Pernambuco, bem como as tendências mais recentes da indústria automobilística diante da crise econômica; por fim, tem-se a seção de considerações finais.

0 objetivo geral deste trabalho é avaliar a viabilidade de instalação em Pernambuco de um centro de desenvolvimento tecnológico de classe mundial, conforme anunciado pela Fiat quando de sua concepção, bem como discutir os fatores que geraram a mudança de planos para com o Centro. Ademais, objetiva mostrar as dificuldades e fragilidades de economias em desenvolvimento no sentido de avançar no quesito capacitação tecnológica e de vir a ter uma dinâmica tecnológica autônoma, a exemplo de alguns outros países fora do chamado "Centro" desenvolvido, numa alusão à conhecida relação Centro versus Periferia, que já superaram essas dificuldades. Nessa direção, parte-se da premissa de que, em épocas de crise, as decisões estratégicas tendem a ser novamente centralizadas na matriz das empresas.

Da mesma forma, tem-se consciência de que, com o falecimento prematuro do Governador Eduardo Campos, liderança que comandou o processo de negociação e implantação da fábrica da FCA, e com a crise econômica que assola Pernambuco, compromissos que haviam sido assumidos pelo governo estadual passam a ser postergados, além de perder-se a liderança maior do processo de negociação com a empresa multinacional. Em outras palavras, economia e política, como de costume, estão juntas também nesse evento e ajudam a entender os avanços e retrocessos em curso.

A estratégia metodológica adotada foi a análise do contexto geral e específico dos planos de instalação do Centro e seus efetivos desdobramentos, com base em entrevistas semiestruturadas com pesquisadores e especialistas da área e de consulta a documentos da FCA e dos órgãos públicos afeitos ao tema. Foram entrevistados Lúcia C. P. de Melo, Secretária de Ciência Tecnologia e Inovação do Estado de Pernambuco, Fernando Buarque, Universidade de Pernambuco (Inteligência Artificial), Egon Luiz Rodrigues Daxbacher, na época Diretor da FCA em Recife e 
Rodrigo J. P. Ferreira do Departamento de Engenharia de Produção da UFPE. ${ }^{3}$ Os documentos consultados estão citados nas Referências, destacando-se SECTI (2017) e FCA (2015), além de outros encontrados nos sites ali listados. ${ }^{4}$

\section{Desenvolvimento local, inovação e competitividade}

A crise capitalista traz, para sua superação, a necessidade de abrir espaço para a introdução do novo, reformulando a base produtiva e introduzindo profundas alterações na dinâmica de desenvolvimento. Se, por um lado, são fundamentais os investimentos privados, por outro, cabe ao Estado, principalmente por meio de políticas públicas e medidas regulatórias, criar condições efetivas para um projeto que permita não só superar a recessão, mas apontar para uma inserção em condições vantajosas no cenário que se construirá a partir da crise.

\section{Segundo Cassiolato e Lastres,}

cabe ao Estado papéis da maior importância, seja como agente estruturante das novas forças produtivas, seja como propulsor e orientador da sua difusão através da economia e sociedade. Constituem um elemento importante dessa visão as coalizões estratégicas entre o Estado e os segmentos da sociedade civil, com objetivos e compromissos recíprocos definidos de forma explícita. (CASSIOLATO; LASTRES, 2005, p.43)

Nesse sentido, estudos diversos apontam para a importância de se garantir uma maior ligação e apropriação dos frutos dos avanços científicos e tecnológicos, que permitam a introdução de inovações e, consequentemente, garantam o crescimento de investimentos e da produtividade, ampliando condições objetivas para o desenvolvimento e para a competitividade.

Cassiolato e Lastres, por exemplo, ressaltam que

a incompreensão das particularidades do processo inovativo e de suas consequências para o desenvolvimento tem levado a equívocos que impedem avançar no sentido de criar propostas e implementações políticas que dêem conta dos desafios e oportunidades colocados atualmente à sociedade e à economia brasileira. (CASSIOLATO; LASTRES, 2005, p.35)

Nesse contexto, a preocupação deve se centrar na identificação de prioridades e na definição de planos e programas para o setor de ciência, tecnologia e inovação CT\&I, consentâneos com as diretrizes das áreas produtivas.

3 Ressalte-se que os entrevistados não têm, necessariamente, a mesma visão dos autores sobre o tema.

4 Foram utilizadas neste trabalho as informações secundárias e bibliográficas disponíveis, que são ainda restritas e limitadas a documentos da FCA e do Governo de Pernambuco. 
Assim, é fundamental articular o desenvolvimento local com estratégias de inovação que garantam a competitividade. Para tal, faz-se necessário consolidar um Sistema Local de Inovação robusto que dê suporte aos investimentos estratégicos. Nas palavras de Fernandes (2016):

O Sistema Territorial de Inovação (STI), consiste no conjunto de componentes e das relações entre eles, cujas atividades e interações buscam promover a apropriação, o desenvolvimento e a difusão de tecnologias e inovações em um determinado território. Esses sistemas territoriais podem estabelecer relações com elementos de outros sistemas, em escalas mais e menos abrangentes. As decisões dos componentes do sistema são condicionadas pela disponibilidade de recursos, sendo esta função de fatores institucionais, histórico-culturais, econômicos e de infraestrutura. Além disso, são ainda influenciadas pelos distintos interesses que movem os agentes locais e externos. Dessa forma, sistemas territoriais envolvem disputas em torno de escolhas relacionadas ao desenvolvimento endógeno ou à importação de tecnologias. Diferem de lugar para lugar e, assim, contribuem para a construção de diferentes trajetórias territoriais. A Figura 1 ilustra esse raciocínio. (FERNANDES, 2016, p. 18)

Como se sabe e é importante ressaltar, a concorrência na sociedade moderna não se manifesta por meio de preços menores. É fundamental, entre outras estratégias, abrir novos mercados e para tanto é fundamental diferenciar-se dos concorrentes reais ou potenciais, o que exige aumentos de produtividade.

$\mathrm{Na}$ verdade, o principal traço da concorrência é a multiplicidade dos instrumentos associados à busca permanente de diferenciação por parte das empresas. 0 aspecto fundamental a se captar é que se está tratando de um processo evolutivo em que as empresas precisam crescer em escala e em produtividade para se diferenciarem (SECTI, 2017).

Para Schumpeter (1984), o impulso fundamental que inicia e mantém em movimento o processo capitalista é a busca do novo. E esse novo pode ser variado: novos bens de consumo; novos métodos de produção; novos métodos de transporte; novas formas de organização industrial; novas tecnologias, entre outros. 
Figura 1: Esquema ilustrativo do conceito de Sistema Territorial de Inovação

Sistema de Inovação

Complexa e dinåmica interaçảo de entidades constituintes no espaço

sistema de inovação $=$ componentes + relaçōes internas e externas

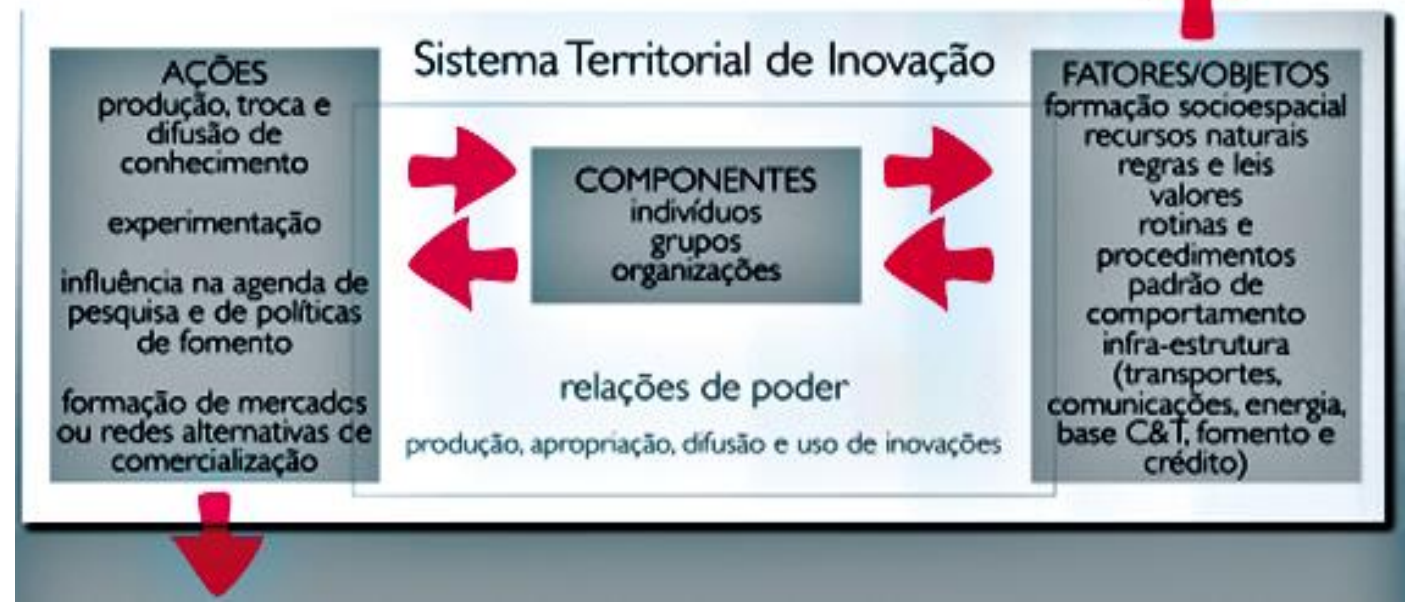

Fonte: Fernandes (2016)

As lições schumpeterianas apontam para o entendimento de que, nas sociedades capitalistas contemporâneas, para haver desenvolvimento, é fundamental garantir as condições para a busca do novo, seja através de incentivo à criação de uma cultura inovadora, seja no estímulo ao crescimento do perfil inovador na classe empresarial, ou através de mecanismos de financiamento e crédito que estimulem a busca da inovação. Com esse quadro em mente, avaliar se há condições, em uma determinada localidade, de inserção competitiva, passa necessariamente por criar efetivas condições para o processo inovativo e para a busca do novo.

Nesse sentido, em anos recentes, o Governo do Estado de Pernambuco adotou uma forte política de atração de empresas de maior porte, mudando a matriz produtiva do Estado. Para dar apoio a esse movimento e consolidar a dinâmica econômica e de inovação é fundamental que se implante uma política consistente, tendo como parâmetros a articulação entre setor produtivo, comunidade acadêmica e instituições de Governo.

No mundo atual, as tecnologias dominantes passam pela convergência de diferentes áreas como tecnologias da informação, eletrônica, mecânica e design, 
entre outras. É preciso, portanto, um ambiente e instrumentos de política pública que garantam à sociedade se beneficiar dos ganhos advindos das novas tecnologias e do novo perfil da indústria manufatureira. Preparar o território estadual para esse novo perfil concorrencial passa por dar condições efetivas para as empresas se inserirem competitivamente, com níveis de produtividade compatíveis com os apontados pela nova matriz tecnológica que vem se consolidando, ou seja, capacitá-las para o futuro competitivo.

Nesse contexto, a implantação de Centros de Desenvolvimento de grandes empresas no território pernambucano é, sem dúvida, fator agluinador de esforços para a construção de um Sistema Local de Inovação mais estruturado. Daí a importância de se garantir a sua efetiva implantação nas franjas do processo de atração de grandes projetos industriais, como é o caso da FCA, com base em pesados investimentos governamentais e em generosos incentivos fiscais, sejam eles estaduais ou federais.

Deve-se aqui ressaltar que a literatura econômica a respeito das possibilidades de espraiamento da capacitação e dinâmica tecnológica autóctone na periferia tende a ter, com alguma frequência, um viés de ceticismo. Autores como Furtado, por exemplo, questionam a possibilidade de endogeneização do progresso técnico com base nas empresas multinacionais. Por sua vez, Cassiolato e Lastres (2015) argumentam que, com a maior internacionalização a partir dos anos 1990, a economia brasileira sofre progressiva deterioração do tecido industrial e que as atividades tecnológicas das subsidiárias das empresas multinacionais são de caráter mais adaptativo (melhorias de produto e de processo), representando essa maior internacionalização um

\footnotetext{
empecilio ao desenvolvimento tecnológico e inovativo local” (p.192). (...) "O país continua com baixa importância relativa nas atividades intensivas em tecnologia, tendo perdido, de fato, capacidade tecnológica em diferentes sistemas produtivos e inovativos (CASSIOLATO; LASTRES, 2015, p. 194).
}

Nesse mesmo artigo, os autores citados revisam o olhar de Furtado sobre o tema e afirmam: "Furtado passa a introduzir nas suas construções a temática de como as empresas transnacionais bloqueiam a endogeneização do progresso técnico e a própria constituição do centro dinâmico na estrutura produtiva brasileira" (CASSIOLATO; LASTRES, 2015, p.202). ${ }^{5}$

5 Mais adiante alertam que a internacionalização das atividades de P\&D implica em aquisição por parte das multinacionais de capacitações locais, "especialmente por meio da compra de empresas nacionais, 
Com isso, afirmam a ocorrência da concentração das atividades mais intensivas em conhecimento nas matrizes com o predomínio de atividades menos estratégicas nas subsidiárias.

Essa visão parece pertinente para muitos casos e tem suporte em diversas experiências de empresas multinacionais em países periféricos, porém, não dá conta de casos em contrário. Além disso, cabe aqui chamar atenção para a existência de algumas situações mais recentes, postas pela organização em redes e pela maior competição a nível global, em que se abrem possibilidades de instalação de centros de desenvolvimento tecnológico em subsidiárias, que assim, mesmo de forma seletiva, podem participar do processo inovativo e desenvolver capacitações endógenas.

Esse parece ser o caso da indústria automobilística, que no Brasil vem abrindo em algumas subsidiárias centros de desenvolvimento tecnológico mais ativos e integrados mundialmente. Vide o caso da Fiat, que tem em Betim-MG um desses centros e que planejou e ensaia instalar em Pernambuco um outro centro, que teria características similares, o que será melhor detalhado mais adiante. Cabe aqui ressaltar que essa é uma estratégia de longo prazo, mas que em tempos de crise ocorrem retrocessos e pode haver uma tendência de concentração da pesquisa estratégica nos centros já consolidados. Ainda não se pode afirmar se esse retrocesso é definitivo ou conjuntural; o que se pode dizer é que, no mínimo, leva a um atraso nos cronogramas previstos para transformá-lo em um Centro de Pesquisa Estratégico para a Empresa a nível mundial. Ou seja, mesmo nas situações que parecem contrariar as dificuldades apontadas na literatura, como é o caso aqui analisado, os avanços estão submetidos a postergações ou até a retrocessos em função da conjuntura e das incertezas expostas em momentos de crises. 


\section{As estratégias de inovação da indústria automobilística}

A fase contemporânea do capitalismo tem sido marcada pelo processo de mundialização dos sistemas produtivos, dominado pelas empresas multinacionais no bojo da desregulamentação dos fluxos de bens e serviços e de capitais. Com isso, a produção mundializada e o chamado out sourcing passaram a ser privilegiados, incluindo a deslocalização da produção para países e regiões menos desenvolvidos. Nesse contexto de intensa implantação de subsidiárias de empresas multinacionais na chamada periferia, que inclui sobremaneira a indústria automobilística, as avaliações e análises mais em voga, conforme comentado na seção anterior, apontam para a transferência das linhas de produção, mas atentam para a manutenção em seus países sedes dos centros de pesquisa, desenvolvimento e inovação. Com isso, o controle da parte mais sensível e valiosa da produção mundializada permaneceria nos países desenvolvidos e manter-se-ia a barreira centro versus periferia no campo da tecnologia e da inovação.

Conforme já explicitado, análises mais recentes indicam alguma modificação nesse quadro, pelo menos no que diz respeito à indústria automobilística. Nesse segmento, ainda extremamente dinâmico do ponto de vista tecnológico e do ponto de vista da cadeia produtiva e dos impulsos multiplicativos em termos de emprego e renda, algumas análises e estudos apontam para a descentralização de investimentos em P\&D e constituição de competências tecnológicas nas subsidiárias localizadas em países em desenvolvimento, pelos menos em alguns casos. O Brasil, por suas condições de mercado e de indução de políticas favoráveis a esse segmento parece estar entre tais casos.

0 processo de internacionalização das atividades das empresas multinacionais automobilísticas passou por etapas bem distintas. Se no início a preocupação era apenas com o mercado, com a criação de entrepostos para viabilizar a comercialização de produtos, com o tempo passa-se à dispersão espacial de fábricas, à montagem regionalizada, a incentivos a sistemistas para abrirem filiais próximas às necessidades das novas fábricas, à colaboração para a produção, à integração de sistemistas com sistemas locais de produção, entre outras mudanças.

Um traço que parece característico nessa indústria nos anos mais recentes é o processo chamado de de-maturity (rejuvenescimento) industrial, que vem exigindo intensificação das atividades de P\&D, particularmente nas áreas de informática, eletrônica, telecomunicações e design (Carvalho, 2008).

Ao lado desse processo de rejuvenescimento inovativo, tem sido observada a distribuição espacial de centros de desenvolvimento tecnológico. Considerados 
estratégicos, como fator de diferenciação dos seus produtos no mercado, as empresas mantiveram, por muito tempo, essa atividade associada às suas matrizes procurando evitar dispersão, centralizando a concepção do produto, bem como todo o processo inovativo. Contudo, no sentido de aproveitar capacitações consolidadas em outros espaços, bem como adequar produtos a mercados específicos, do fim do século passado ao início deste século vem sendo notado um movimento de articular e montar alguns centros de desenvolvimento tecnológico em regiões estratégicas.

No caso do Brasil, observa-se que as montadoras e empresas fornecedoras, tendo em vista também a dimensão e expansão do merca do interno,

\begin{abstract}
vêm acumulando competências organizacionais que as capacitam para uma maior inserção na cadeia produtiva global (...) Nesse sentido, destaca-se a presença de subsidiárias inovadoras em âmbito local, regional e global, as quais exercem o papel de Centros de Excelência. Tais empresas exercem a capacidade de desenvolvimento de produtos para o âmbito mundial. Constata-se que as subsidiárias estrangeiras no Brasil estão investindo simultaneamente em P\&D e produção. (ZOROVICH, 2016, p. 3)
\end{abstract}

Essa dinâmica tem a ver, entre outros fatores, com a necessidade de adaptações locais, mas também participa do processo inovativo mais geral das montadoras, em vista da globalização e do acirramento da concorrência, que leva à busca de inovação com base nas redes formadas entre matriz, subsidiárias e fornecedores.

No caso do Brasil, por exemplo, Amatucci e Bernardes (2009), apud Zorovich, 2016, p. 11,

sugerem que as condições da infraestrutura das estradas brasileiras impactam na capacitação da engenharia local, credenciando as subsidiárias das montadoras brasileiras para o desenvolvimento de produtos em função das exigências técnicas que derivam daí. (ZOROVICH, 2009, p. 11)

Pelo que se observa, em termos gerais, outros fatores também atuam a favor de uma maior dinâmica inovativa nas subsidiárias, entre os quais a capacitação local, os acordos e as políticas governamentais etc.

A tendência de desenvolvimento de estratégias tecnológicas, tendo em conta características de mercados específicos, é também apontada por Carvalho (2005), que destaca essa tendência de adaptação de projetos às características e aos gostos locais, com desenvolvimento e introdução de plataformas específicas para países em desenvolvimento, como responsável por bons resultados obtidos no mercado 
brasileiro pela Fiat e pela GM. Para que isso tenha ocorrido, esforços e investimentos em P\&D das subsidiárias locais foram indispensáveis.

Evidentemente, esse processo é seletivo e baseado em contrapartidas bastante significativas das regiões a serem contempladas. Para que uma região possa ter algum desses centros, portanto, precisa contar com condições favoráveis no seu sistema de inovação e, ao mesmo tempo, de articulação política e de incentivos governamentais. Conforme será visto na seção seguinte, essas condições são preenchidas, pelo menos em parte, pela região aqui enfocada, o que levou à inclusão de um centro de pesquisa de âmbito mundial no projeto que levou à implantação da FCA em Goiana-PE, sobre o qual se discorre a seguir.

\section{O ambiente econômico no entorno da FCA}

No território do entorno da fábrica da FCA, envolvendo os Municípios de Goiana, Região Metropolitana do Recife, além dos municípios de Glória do Goitá e Belo Jardim no Agreste de Pernambuco, em 2010, habitavam 3,3 milhões de pessoas, cerca de $34 \%$ da população estadual. 0 território apresentava, em 2012, um valor adicionado de $\mathrm{R} \$ 51,8$ bilhões (52 \% do de Pernambuco), tendo participação mínima de atividades agrícolas $(0,27 \%)$ e com concentração de atividades em indústria (27,27 \% e serviços 72,46 \%). Destaque-se a elevada participação de atividades industriais, que contrasta bastante com o peso da indústria no PIB do Brasil como um todo (cerca de $13 \%$ em 2013) (Tabela 1).

Tabela 1: Território em TI-Automotivo e Pernambuco -Valor Adicionado Bruto total e setorial (mil R\$ de 2000) - 2012

\begin{tabular}{c|c|c|c|c}
\hline \multirow{2}{*}{ Unidade espacial } & \multicolumn{4}{|c}{ Valor Adicionado Bruto } \\
\cline { 2 - 5 } & Total & Agropecuária & Indústria & Serviços \\
\hline \multirow{2}{*}{ PERNAMBUCO } & 99.275 .000 & 2.581 .150 & 27.201 .350 & 69.492 .500 \\
& & & & \\
\hline Território em TI- & 51.815 .792 & 141.952 & 14.129 .243 & 37.544 .597 \\
Automotivo & $52 \%$ & $0,27 \%$ & $27,27 \%$ & $72,46 \%$ \\
\hline
\end{tabular}

Fonte: IBGE/ Cidades@ Estatísticas (2012).

O território em TI-Automotivo de Pernambuco tem como principal suporte a fábrica Jeep da Fiat Chrysler Automobile (FCA), instalada (inaugurada em 28/04/2015) em Goiana. Trata-se de um empreendimento grandioso em termos econômicos. De acordo com o Pressrelease da FCA: 
Quadro 2: Fornecedores no Parque I do Polo Automotivo JEEP - Goiana

\begin{tabular}{|c|c|c|}
\hline Empresa & Produtos & Área $\left(\mathrm{m}^{2}\right)$ \\
\hline Adler Pelzer & Isolamentos, tapetes, forração de teto & 15.850 \\
\hline Brose & Módulos de porta, regulador de janelas & 4.608 \\
\hline Denso & $\begin{array}{l}\text { Climatização (HVAC), arrefecimento do motor } \\
\text { (ECM), módulo frontal (FEM), motor de partida, } \\
\text { alternador, limpador de para-brisa }\end{array}$ & 5.616 \\
\hline Fraurecia Magneti Marelli & $\begin{array}{l}\text { Painel completo, console central, painéis de } \\
\text { portas, para-choques plásticos }\end{array}$ & 54.000 \\
\hline Lear & Bancos & 18.563 \\
\hline Magneti Marelli Stamping & $\begin{array}{l}\text { Estamparia de componentes estruturais e de } \\
\text { suspensão }\end{array}$ & 20.000 \\
\hline Magneti Marelli Welding & $\begin{array}{c}\text { Soldagem de subchassi e componentes } \\
\text { estruturais }\end{array}$ & 12.000 \\
\hline Magneti Marelli PCMA & $\begin{array}{l}\text { Tanques plásticos de combustível, montagem de } \\
\text { pedaleira }\end{array}$ & 11.520 \\
\hline $\begin{array}{l}\text { Magneti Marelli Suspension } \\
\text { Assembly }\end{array}$ & $\begin{array}{c}\text { Montagem do sistema de suspensão com mola, } \\
\text { amortecedor, braço oscilante, disco e pinças de } \\
\text { freios }\end{array}$ & 11.520 \\
\hline $\begin{array}{c}\text { Magneti Marelli } \\
\text { SuspensionWelding }\end{array}$ & Soldagem do sistema de suspensão & 10.368 \\
\hline Piralli & Montagem de pneus em rodas & 5184 \\
\hline PCM & $\begin{array}{l}\text { Subconjuntos soldados estruturais de chassi e } \\
\text { das estruturas dos bancos }\end{array}$ & 23000 \\
\hline Revestcoat & $\begin{array}{l}\text { Tratamento superficial de peças metálicas, } \\
\text { montagem de subcomponentes, aplicação de } \\
\text { adesivos em peças de reposição, preparação de } \\
\text { embalagens de peças de reposição }\end{array}$ & 13.096 \\
\hline Magneti Marelli Sole Prima & $\begin{array}{c}\text { Peças plásticas de acabamento incluindo colunas } \\
\text { internas, tampa interna do porta-malas, protetor } \\
\text { de cárter, molduras externas, caixas de rodas }\end{array}$ & 20.736 \\
\hline Saint Gobain Sekurit & Montagem e preparação de vidros & 3.456 \\
\hline Tiberina & Conjuntos soldados estruturais de chassi & 18.432 \\
\hline Total & & 247.949 \\
\hline
\end{tabular}

Fonte: FCA (2015). 


\begin{abstract}
A fábrica Jeep ocupa uma área construída de 260 mil metros quadrados e tem capacidade para produzir 250 mil veículos por ano. No perímetro fabril, ergue-se também o Parque de Fornecedores, um complexo de 12 edifícios, que abrigam 16 empresas responsáveis por 17 linhas de produtos. 0 Parque de Fornecedores ocupa uma área de 270 mil metros quadrados. Hoje, o empreendimento emprega cerca de 7 mil pessoas entre planta Jeep, Parque de Fornecedores e serviços gerais. Deste contingente, 82\% são nordestinos e 78\%, pernambucanos. (FCA, 2015)
\end{abstract}

Tendo em conta dados sintetizados de um documento elaborado pela Ceplan/Diagonal para a Secretaria de Planejamento de Pernambuco, ${ }^{6}$ o investimento total da planta, até 2018 , deverá ser de $\mathrm{R} \$ 9,6$ bilhões, sendo $\mathrm{R} \$ 4,4$ bilhões em obras e edificações e $\mathrm{R} \$ 5,2$ bilhões em máquinas e equipamentos. Estima-se um impacto de cerca de 6,5 \% sobre o PIB do Estado para os anos de 2019 e 2020.

Um aspecto importante em termos de impactos econômicos é o índice de nacionalização de $70 \%$, sendo previsto chegar a $80 \%$ a partir de fornecedores, principalmente, de Pernambuco, São Paulo e Minas Gerais (FCA- Pressrelease). Sobre isso, vale chamar atenção para a possível repercussão da FCA sobre empresas já instaladas em Pernambuco que poderão fornecer peças e componentes, além da instalação junto com a mesma de 16 empresas sistemistas (Quadro 2) e de outras previstas para serem ainda instaladas. Além disso, o segmento de TI dessa sub-região tem já uma base significativa de empresas em funcionamento e encontra no Porto Digital e no Cesar (Centro de Estudos e Sistemas Avançados do Recife), sediados no Recife, suas principais bases. Há, nesses casos, uma forte integração com o Centro de Informática da Universidade Federal de Pernambuco-UFPE, principalmente no caso do Cesar-, empresa criada por professores da UFPE.

Destaque-se que o ambiente do Porto Digital, uma iniciativa do Governo de Pernambuco, criado no ano 2000, que abriga 316 empresas na área de Tecnologia da Informação e Comunicação (TIC), foi outro fator que atraiu a FCA para o estado. Sobre a base de C,T\&I, adianta-se mais informações a seguir.

\title{
4.1 Características da base de C, T \& I no sistema de inovação em TI-Automotivo
}

No território em torno da FCA existe uma ampla base de instituições de ensino e pesquisa que podem ser mobilizadas para a ativação do sistema local de inovação. Com efeito, chegam a 100 as unidades de formação em Ensino Superior no território, das quais 72 localizadas no Recife, 12 em Olinda e 6 em Jaboatão dos Guararapes, com as outras espalhadas em mais 5 municípios. (MEC, 2015)

6 Disponível em: http://pt.slideshare.net/redacaojornaldocommercio/apresentaoimprensasintticarev 
No diretório de grupos de pesquisa do CNPq estavam cadastrados em 2015, no território de Pernambuco, um total de 1.619 grupos de pesquisa, sendo destes 828 da UFPE (51,1 \%), 217 da Universidade Federal Rural de Pernambuco-UFRPE $(13,4 \%)$ e 160 da Universidade de Pernambuco-UPE (9,8 \%). Ou seja, 74,3\% dos grupos de pesquisa localizam-se nessas três instituições. Tendo em conta as áreas selecionadas como de mais afinidade ${ }^{7}$ com o setor automobilístico, observa-se que na UFPE encontram-se 136 grupos de pesquisa, 24 na UFRPE e 15 na UPE.

Esses números podem ser mais bem especificados ao olhar o número de programas de pós-graduação. As instituições de ensino e pesquisa da região abrigam 103 programas acadêmicos de mestrado e/ou doutorado e 20 mestrados profissionais, onde militam 2.912 docentes, números bastante significativos, portanto. Como era de se esperar, os programas acadêmicos estão concentrados nas três universidades públicas: 60 na UFPE, 26 na UFRPE e 9 na UPE. Nos programas de pós-graduação da UFPE haviam 1.592 docentes entre permanentes, colaboradores e visitantes, enquanto na UFRPE estavam 696, havendo ainda 189 na UPE. Como nesses programas concentram-se os pesquisadores, deve-se buscar, prioritariamente, nessa base das três instituições líderes as possíveis articulações para a ativação do sistema de inovações no território em TI-Automotivo.

Além das universidades e instituições de ensino superior já mencionadas, há um número significativo de instituições mais voltadas para a formação tecnológica. Entre estas estão o Instituto Federal de Pernambuco- IFPE, que oferece cursos técnicos em 10 áreas diversas, além de Cursos Superiores em Tecnologia em Análise e Desenvolvimento de Sistemas; e Tecnologia em Design Gráfico. Outro destaque nessa área técnica vai para o Serviço Nacional de Aprendizagem Industrial- Senai que tem 6 unidades em municípios diversos do STI, ofertando cursos em 13 áreas selecionadas por afinidade com o STI nos níveis de aprendizagem (31 cursos), qualificação (130 cursos), técnico (17 cursos) e superior (1 curso em Automação e Mecatrônica).

Afora essas instituições e além do Cesar e do Porto Digital, cabe ainda destacar o Instituto Tecnológico de Pernambuco - Itep. Nos laboratórios do Itep são feitas calibrações, análises e ensaios, estudos e avaliações e inspeção e fiscalização, estando ainda no seu âmbito de atribuições a oferta de cursos e alguns centros tecnológicos em regiões diversas do Estado.

Pelo visto acima, o território aqui estudado apresenta potencialidades evidentes no seu sistema local de inovações, ao lado de desafios marcantes no sentido de integrar-se com mais densidade com o segmento automobilístico, porém já há indicações de que essa integração está em curso, principalmente com a instalação em

\footnotetext{
7 Áreas seguintes: Ciência da Computação, Ciência da Informação, Comunicação, Desenho Industrial, Engenharia Elétrica, Engenharia Mecânica, Engenharia Química, Engenharia de Materiais e Metalúrgica, Engenharia de Produção, Engenharia de Transportes e Química.
} 
andamento do Centro de Pesquisa da FCA cujos primeiros links já são perceptíveis no Porto Digital. As dificuldades maiores parecem estar na aproximação dos pesquisadores da base de C\&T com as empresas do segmento, a levar em conta o que já se sabe sobre a pouca interação entre instituições de ensino e pesquisa no Brasil, particularmente em Pernambuco.

\subsection{O Centro de pesquisa da FCA}

O anúncio de que a Fiat Chrysler Automobile (FCA) traria para Pernambuco um Centro de Pesquisa Automotivo gerou expectativas de reforço da dinâmica de inovação para o Estado, permitindo antever um processo virtuoso em que seriam atraídos profissionais altamente qualificados e projetos de importância e escala mundial ${ }^{8}$. Assim, admitia-se que tal Centro seria um passo mais importante do que a própria vinda da fábrica automobilística, dados os efeitos multiplicadores que se anteviam na interação com entidades do conhecimento, sistemistas e com outras indústrias que já estão ou viriam a se instalar no Estado.

Cabe ainda destacar, que o desenvolvimento tecnológico no setor automobilístico em Pernambuco não se atém apenas ao Centro da FCA. Exemplo emblemático é o da empresa Acumuladores Moura, que estruturou um instituto para atender às necessidades de pesquisa e inovação da empresa, fabricante de baterias, principal objeto das pesquisas e projetos. 0 projeto de fazer o Instituto surgiu em 2013, em que a maioria das pesquisas e projetos envolvidos tratam de aplicações em baterias usadas por veículos e outras por empresas que gerem energia eólica ou solar. No período atual, estão sendo desenvolvidas pesquisas sobre as baterias para carros híbridos ${ }^{9}$.

Com a vinda do Centro Tecnológico da FCA, vislumbrava-se a perspectiva de empresas fornecedoras trazerem para a região seus desenvolvimentos na área tecnológica, o que capitaneado pela Fiat Chrysler permitia antever um centro mundial para o setor automotivo pernambucano.

No entanto, esse anúncio, feito em dezembro de 2013, não tinha em sua perspectiva, nem seria previsível na época, a crise econômica com a qual o País viria a se confrontar a partir de fins de 2014. Neste texto, além de explicitar a concepção original, pretende-se apresentar alguns dos impactos preocupantes que já começam a ser notados, advindos da situação econômica que o Brasil e, consequentemente, Pernambuco, vêm enfrentando.

8 A respeito da atração de Centros de Pesquisa e Inovação, bem como de sua importância para o estado de Pernambuco, ver Secti, 2017, p.38.

9 Jornal do Commercio, Recife, 16/08/2015. 


\subsection{Concepção do centro da FCA}

A FCA, antes de se instalar em Pernambuco, já possuía três Centros de P\&D: Turim (Itália), Auburn Hills (EUA) e Betim (Minas Gerais). Com a implantação da fábrica em Goiana, foi decidido que seria implantado um quarto Centro, dessa vez nesse Estado. A existência de um Polo consolidado na área de tecnologia da Informação, bem como o fato da empresa ter ali construído sua fábrica mais moderna, além de a robótica e a manufatura avançada serem a base do processo produtivo automotivo, muito influenciaram nessa decisão.

Nesse sentido, havia a preocupação de instalar em Pernambuco um polo com um conjunto de profissionais altamente qualificados e laboratórios de última geração. Estrategicamente, decidiu-se que esse Centro de Pesquisas teria quatro características principais ${ }^{10}$ :

- Desenvolvimento de veículos, motores e transmissões com ênfase em software embarcados e em powertrain;

- Consolidação de Pernambuco como um Centro de Tecnologia Automotiva;

- Atração e capacitação de profissionais capacitados;

- Sinergia com outros centros de P\&D da FCA.

Na concepção original, se tinha em mente ser possível trazer projetos de quatro segmentos relevantes para a empresa, aliados à estratégia mundial: simulação, softwares embarcados, powertrain e combustíveis renováveis. Aliados a isso, pretendia-se criar um Centro de Formação para Engenheiros de Classe Mundial, articulado ao Instituto Politécnico de Turim.

Para a realização desse empreendimento, inicialmente, chegou-se a cogitar a reestruturação de um prédio antigo na área central da cidade do Recife, a outrora fábrica da Tacaruna. No entanto, dadas as resistências políticas existentes, bem como os custos envolvidos, optou-se em estruturá-lo em quatro unidades distintas e integradas:

\section{Centro de software (Laboratório de Inovação Veicular - Live)}

0 Centro de Software foi localizado no Porto Digital e vem se concretizando por meio do Laboratório de Inovação Veicular - Live. Foi Implantado em junho de 2016. Realizado em parceria junto ao Centro de Informática da UFPE e Iron House (Empresa de Desenvolvimento Imobiliário do Grupo Cornélio Brennand), visando o desenvolvimento de vários tipos de softwares embarcados, sendo capazes de criar novos conceitos, protótipos e validação de uso por meio digital e contribuir com o

\footnotetext{
${ }^{10}$ FCA Release, $02 / 12 / 2015$.
} 
desenvolvimento de mão de obra na área automotiva no Estado e no Brasil. Já conta com mais de 150 profissionais, entre os quais cerca de 80 engenheiros, em suas instalações, a maioria com qualificação de mestrado e doutorado.

\section{Unidade de projetos}

Responsável pela concepção e elaboração dos desenhos dos componentes, motores e transmissões de operação computadorizadas. Atualmente, encontra-se instalada no Paiva, município de Jaboatão dos Guararapes, baseada em Engenharia de Software, onde já atuam cerca de 70 engenheiros. Essa unidade encontra-se ainda em fase de estruturação.

\section{$>$ Centro de testes veiculares}

É etapa básica para articulação do centro de projetos com o campo de prova. Local onde veículos destinados ao desenvolvimento (não comerciais) e os protótipos são testados (teste de tráfego nas ruas, análise de materiais, bem como ensaios de laboratórios). Esse centro é responsável pela finalização do desenvolvimento de motores powertrain (conjunto de motor e transmissão). Sua implantação está postergada principalmente pelos efeitos da crise do país, o que, de certa maneira, posterga a pretensão de Pernambuco sediar o quarto centro de pesquisa mundial da FCA.

\section{$>$ Campos de prova}

Localizado no perímetro do Polo Automotivo, com construção já iniciada, é constituído por um conjunto de pistas e laboratórios a céu aberto que permitirão o aprimoramento e garantia dos veículos. Com concepção moderna, permitirá o teste de diferentes modelos da montadora e sua proximidade com os sistemistas que lá vêm se constituindo, permitirá grande interação para o aperfeiçoamento dos modelos. 0 campo vai contribuir também para o desenvolvimento de novos produtos em menor tempo e com maior precisão.

Do planejado, notam-se já sinais de arrefecimento, pelo menos no ritmo de implantação. Os projetos de powertrain voltam a ser concentrados em Minas Gerais; avança-se em projetos de simulação, mas com um foco prioritário na América Latina; na área de combustíveis renováveis, define-se um projeto para uso do álcool que, evidentemente, não é uma estratégia mundial; e apenas na área de softwares embarcados notam-se avanços muito significativos, mas em projetos tradicionais, nem sempre com inovações radicais.

Deve-se ressaltar ainda que o projeto de criar um Centro de Formação de Engenheiros de Classe Mundial pouco avançou, embora tratativas tenham sido feitas com instituições como o Serviço Nacional de Aprendizagem Industrial-Senai e o Centro de Estudos Avançados do Recife-Cesar. Também, o Centro perde muito de sua autonomia com uma reestruturação administrativa da empresa que atrela algumas 
gerências locais a Betim, Minas Gerais, e com a extinção da Diretoria de Inovação da FCA em Goiana.

Por fim, não se deve deixar de destacar a pequena interação, até o momento, com as empresas locais. Mesmo com uma empresa de porte mundial como a Baterias Moura, praticamente, não se verificam projetos conjuntos e articulação maior em desenvolvimentos estratégicos.

Cabe notar, no entanto, a importância da vinda do Centro para Pernambuco. Inúmeros são os impactos já notados. Na geração de empregos de alta qualificação, cerca de 150 engenheiros foram contratados. Na articulação com as empresas de maior porte da área de Tecnologia da Informação, deve-se ressaltar os projetos já elaborados ou em elaboração com o Cesar, inclusive de capacitação de recursos humanos. Também, institucionalmente, a localização de laboratórios no Porto Digital, fez com que projetos de manufatura avançada, inclusive com articulação de IoT (internet das coisas) com design e impressão tridimensional, fossem desenvolvidos. A articulação com universidades locais fez com que, em parceria com a Fundação de Amparo à Ciência e Tecnologia de Pernambuco-Facepe, dois importantes projetos estejam sendo desenvolvidos. Um com a UFRPE para capacitação de especialistas automotivos em cinco áreas novas para o Estado e outro de pesquisa com a UFPE para motores de maior sustentabilidade ambiental.

Vale ressaltar que a concepção do Centro da FCA teve em conta a estratégia de pesquisa tecnológica da própria empresa, dentro das mais recentes estratégias inovativas das montadoras de automóveis em termos mundiais, mas também foi influenciada por algumas políticas públicas já então em andamento na área de C, T\&I. Sobre isso, discorremos a seguir.

\subsection{Políticas públicas articuladas ao centro de pesquisa: legislação de incentivo}

Visando o incentivo e consolidação de uma área de pesquisa e desenvolvimento, bem como incentivar investimentos em inovação por parte do setor privado, foram criadas nos últimos 10 anos pelo Governo Federal e Governo Estadual, algumas legislações fortemente direcionadas ao tema.

No âmbito do governo federal, devem ser destacadas a Lei do Bem e a Lei de Informática, além da Inovar-Auto. Também, faz-se necessário destacar agentes financeiros que viabilizam os incentivos como BNDES (Banco Nacional de Desenvolvimento Econômico e Social), BNB (Banco do Nordeste do Brasil) e Sudene (Superintendência de Desenvolvimento do Nordeste).

A Lei 11.196/05, conhecida como "Lei do Bem", criou incentivos fiscais às pessoas jurídicas que realizam pesquisa e desenvolvimento de inovação tecnológica. Para credenciarem-se a esses incentivos, as empresas devem ter lucro contábil, investir em P\&D e trabalhar no regime de lucro real. Um dos objetivos principais da 
lei é aproximar as universidades e institutos de pesquisa das empresas aumentando a possibilidade de resultados reais no processo de inovação.

A Lei de Informática concede incentivos fiscais para empresas que tenham por prática investir em Pesquisa e Desenvolvimento nas áreas de hardware e automação. Esses incentivos fiscais referem-se à redução do IPI em produtos habilitados/incentivados. A indústria nacional que desejar auferir esses incentivos deve comprovar regularidade fiscal, investimentos efetivos em P\&D e atender a uma lista de produtos especificada na lei.

O Programa de Incentivo à Inovação Tecnológica e Adensamento da Cadeia Produtiva de Veículos Automotores (Inovar-Auto) é o regime automotivo que tem como objetivo a criação de condições para o aumento de competitividade no setor automotivo, produzir veículos mais econômicos e seguros, investir na cadeia de fornecedores, em engenharia, tecnologia industrial básica, pesquisa e desenvolvimento e capacitação de fornecedores. A elevação do padrão tecnológico dos veículos, de suas peças e componentes, bem como o aumento da segurança destes são os objetivos principais do programa. Evidentemente, a pesquisa e o desenvolvimento passam a ser pontos básicos para a concepção desses objetivos.

Cabe salientar que, para o financiamento das atividades de inovação e pesquisa, os órgãos federais como BNDES e Sudene/BNB têm sido as principais fontes de recursos.

Do ponto de vista local, o Governo do Estado de Pernambuco, visando incentivar os investimentos em pesquisa, desenvolvimento e inovação, instituiu a obrigatoriedade de investimentos nessas áreas por contribuinte do ICMS beneficiário de incentivo fiscal, bem como o Fundo de Inovação do Estado de Pernambuco - InovarPE.

O setor automotivo e os respectivos insumos e componentes para os estabelecimentos industriais, comércio atacadista de veículos nacionais ou importados e para as empresas sistemistas são os beneficiários do Prodeauto. No caso dos estabelecimentos industriais, onde a Fiat/CHRYSLER está inserida, permite o mesmo que o crédito presumido seja equivalente a 95\% do saldo devedor do ICMS e o diferimento do recolhimento do saldo devedor do ICMS de responsabilidade direta, para o último dia útil do centésimo mês subsequente ao do respectivo período de apuração, além do diferimento do recolhimento do ICMS incidente na importação de produto intermediário, embalagem, parte, peça, acessório, componente, matériaprima e qualquer outro insumo, destinados à aplicação no respectivo processo industrial.

Como contrapartida para o Desenvolvimento tecnológico da cadeia produtiva automotiva no Estado, o Inovar-PE, a lei 15063 de setembro de 2013 estabeleceu que as indústrias beneficiadas por programas estaduais de incentivos fiscais, como o Prodeauto, entre outros, teriam a obrigatoriedade de investir um percentual de seu faturamento em projetos de pesquisa, desenvolvimento e inovação. 
A esses incentivos e fontes de financiamento, juntava-se também um ambiente econômico e institucional favorável ao dinamismo tecnológico no Estado de Pernambuco, notadamente na Região Metropolitana do Recife, o que já foi objeto de análise numa seção anterior deste trabalho.

Mesmo com a confluência de fatores favoráveis, como visto acima, o Centro da FCA não se confirmou, pelo menos por enquanto, como estava previsto. De acordo com as informações coletadas em documentos oficiais e em entrevistas com pesquisadores da área e com executivos da FCA que dão suporte a esse trabalho, as razões para isso associam-se, principalmente, com o desenrolar da crise econômica, que afeta fortemente a economia brasileira e a de Pernambuco em particular. Com isso, as finanças estaduais e federais não dão conta de contrapartidas previstas em infraestrutura (a construção do Arco Metropolitano, por exemplo) e em capacitação e formação de mão de obra. Por outro lado, a FCA, diante dos volumosos investimentos necessários para a instalação plena do Centro num momento de retração do mercado, resolveu reestruturar suas atividades de P\&D, concentrando no Centro de Betim boa parte do que estava previsto para ser desenvolvido no Recife.

0 caso em estudo, portanto, mostra a existência de oportunidades de desenvolvimento tecnológico periférico a partir das subsidiárias de empresas multinacionais, notadamente no setor automobilístico, porém demonstra também a dependência dessas oportunidades a fatores conjunturais e a articulações políticas e capacidade financeira dos governos dos países hospedeiros.

\section{Considerações finais}

Com a crise da economia brasileira, a partir de 2014, verifica-se que o Centro de $\mathrm{P} \& \mathrm{D}$ tem evoluído em ritmo menor do que o previsto. 0 número de cerca de 150 engenheiros atualmente é menor do que se planejava. A unidade de desenvolvimento do powertrain está em compasso de espera, levando a impactos também menores do que o previsto. Além disso, promessas feitas como a infraestrutura adequada com a construção do Arco Metropolitano para facilitar a logística de escoamento e recepção de materiais e produtos pelo Porto de Suape, ou programas de capacitação como a criação do Curso de Formação de Engenheiros de Classe Mundial, pouco avançam.

Outro aspecto importante a destacar é o questionamento quanto às medidas de proteção industrial advindas dos programas de incentivo, principalmente o inovarauto, a lei do bem e a lei de informática. A Organização Mundial do Comércio (OMC) vem estudando o assunto e pode levar a novos adiamentos do projeto original e de seus impactos previstos.

No entanto, deve-se ressaltar que o que já foi instalado tem significância para Pernambuco em uma época de forte crise e retração em sua indústria.

0 Governo de Pernambuco fez um esforço muito grande para atrair um centro Mundial da FCA. Houve compromissos com capacitação de recursos humanos, com 
investimentos em inovação, com concessão de espaços físicos, com articulação de logística. Além disso, contando com uma base em Tecnologia da Informação reconhecida, passou a ser ponto de referência para a fábrica no setor.

Como contrapartida, a FCA comprometeu-se em criar um Centro de Pesquisa que estivesse fortemente articulado à estratégia mundial do grupo. Participar-se-ia, não só do desenvolvimento do software embarcado dos produtos, mas também, da lógica dos motores, do powertrain, da concepção dos novos produtos. Para isso, criou uma Diretoria de Inovação na fábrica pernambucana, além de reformular espaços e contratar mais de 400 engenheiros para trabalhar em desenvolvimento.

Na prática, o planejado não se confirmou e a crise econômica fez com que se diminuísse, em muito, os investimentos previstos do Estado, nas diferentes áreas. A própria concepção do Centro de Desenvolvimento parece ter mudado. Passa de uma concepção de Centro Mundial, no máximo, para um Centro adaptativo para mercados específicos, muito mais focado em projetos para o mercado brasileiro e da América Latina. Não participa assim da definição da estratégia mundial do grupo. 0 grande avanço notado é em projetos na área de tecnologia da informação e simulação. A estratégia atual baseia-se na encomenda de produtos específicos, caracterizando-se a ação no Estado, como um polo de projetos offshore, mas com uma pequena participação na definição das estratégias do grupo na área de desenvolvimento de produtos.

Isso fez com que o grupo empresarial da FCA repensasse sua atuação. A Diretoria de Inovação foi desativada e a área ficou articulada ao Centro de Betim em Minas Gerais, as ações de desenvolvimento vão se concentrando na área de tecnologia da informação, e a participação na concepção dos novos produtos é postergada. Sem dúvida, continuará tendo um impacto significativo na economia pernambucana, mas não o que se imaginava a princípio.

Algumas ilações a partir desse caso em estudo podem ser apontadas. Uma delas: não é sempre verdade que as empresas multinacionais mantêm em suas matrizes o "coração" da pesquisa e desenvolvimento. No caso das montadoras de automóveis, por exemplo, nota-se alguma descentralização e na economia brasileira vêm sendo instalados Centros de Excelência, não apenas pela FCA (ZOROVICH, 2016).

Outra: para que isso ocorra, políticas específicas se fazem necessárias, a exemplo das que vêm sendo adotadas no Brasil, mas que podem ser aperfeiçoadas para que sejam mais efetivas no que diz respeito ao desenvolvimento tecnológico e a contrapartidas aos volumosos incentivos oferecidos.

A experiência de Pernambuco, ademais, mostra que não bastam articulação política e ter uma base favorável de C\&T, pois, na verdade, as condições de mercado e as estratégias de inovação da indústria automobilística é que terminam determinando a efetiva descentralização de centros de pesquisa. Nesse sentido, cabe aos governos locais que negociaram e concederam incentivos, generosos, diga-se, pressionar politicamente para que as tratativas se confirmem. Nessa direção, trazer projetos de 
classe mundial na área de pesquisa e desenvolvimento passa, sem dúvida, por novos investimentos em capacitação de pessoal e infraestrutura laboratorial, o que necessitaria de pesados investimentos difíceis de manter em épocas de forte crise econômica, principalmente em regiões com graves problemas advindos do subdesenvolvimento.

Apesar disso, a experiência em andamento é importante em termos de suas repercussões, mesmo limitadas, mostrando ainda que arranjos mais favoráveis aos países hospedeiros de subsidiárias de empresas multinacionais podem ser vislumbrados e efetivados quando há determinação política e condições objetivas para tal.

\section{Referências}

AMATUCCI, M.; BERNARDES, R. C. . O Novo Papel das Subsidiárias de Países Emergentes na Inovação em Empresas Multinacionais o caso da General Motors do Brasil. RAI :Revista de Administração e Inovação, v. 4, p. 5-16, 2007.

CASSIOLATO, J.E.; LASTRES, H.M.M. SISTEMAS DE INOVAÇÃO E DESENVOLVIMENTO as implicações de política, São Paulo em Perspectiva, v.19, n1, p34-35, jan-mar 2005. DOI: https://doi.org/10.1590/S0102-88392005000100003 Celso Furtado e os Dilemas da Indústria e Inovação no Brasil, Cadernos do Desenvolvimento, Rio de Janeiro, vol. 10 n. 17, PP 188-213, dez 2015.

CARVALHO, E. G. de, Inovação Tecnológica na indústria automobilística: características e evolução recente, em Economia e Sociedade, v. 17, n. 3 (34), p. 429 461, dez 2008. DOI: https://doi.org/10.1590/S0104-06182008000300004

Globalização e Estratégias competitivas na indústria automobilística: uma abordagem a partir das principais montadoras instaladas no Brasil, em Gestão e Produção, v. 12, n.1, p. 121-133, jan-abr 2005. DOI: https://doi.org/10.1590/S0104530X2005000100011

DGP/CNPq, Diretório de Grupos de Pesquisa. Base Corrente, 2015. Disponível em: <http://dgp.cnpq.br/dgp/faces/consulta/consulta_parametrizada.jsf >.

FERNANDES, A. C. Sistema territorial de inovação ou uma dimensão de análise na Geografia contemporânea. In: SPOSITO, E. S.; SILVA, C. A.; NETO, J. L. S.; MELAZZO, E. 
S. (Orgs). A diversidade da Geografia Brasileira. Rio de Janeiro: Consequência Editora, 2016. p. 113-142

FURTADO, C., El subdesarrollo latinoamericano. Ensayos de Cels Furtado. México: Fondo de Cultura, 1983.

IBGE, Instituto Brasileiro de Geografia e Estatística. Censo Demográfico, 2010. Disponível em: <http://www.ibge.gov.br/home/estatistica/populacao/censo2010/>.

IBGE, Instituto Brasileiro de Geografia e Estatística. Censo Demográfico, 2000. Disponível em: <http://www.ibge.gov.br/home/estatistica/populacao/censo2000/>.

IBGE, Instituto Brasileiro de Geografia e Estatística. Censo Demográfico, 1991. Disponível em: <http://www.ibge.gov.br/home/estatistica/populacao/censodem/ default_censo1991.shtm>.

IBGE, Instituto Brasileiro de Geografia e Estatística. Cidades@ Estatísticas, 2012. Disponível em: <http://www.cidades.ibge.gov.br/xtras/home.php>.

IFPE, Instituto Federal de Educação, Ciência e Tecnologia de Pernambuco. Cursos e unidades do IFPE, 2015. Disponível em: <http://portal.ifpe.edu.br/cursos/index.jsf? campi=Reitoria $>$.

ITEP, Instituto Tecnológico de Pernambuco Disponível em: <http://www.itep.br/ index.php/o-itep/a-instituicao>.

FCA, Press release Institucional do Polo Automotivo Jeep. Goiana: FCA, 2015.

/LATAM, Centro de Pesquisa, Desenvolvimento, Inovação e Engenharia Automotiva de Pernambuco, http://mundofca.com/centro-de-pesquisadesenvolvimento- inovacao-e-engenharia-automotiva-de-pernambuco/.

MEC, Ministério da Educação. E-MEC - Instituições de Educação Superior e Cursos Cadastrados, 2015. Disponível em: <http://emec.mec.gov.br>

MTE, Ministério do Trabalho e Emprego. Base estatística online da Relação Anual de Informações Sociais - RAIS, 2015. Disponível em: <http://sgt.caged.gov.br>.

OCDE. Science, Technology andIndustryScoreboard. Paris: OCDE, 2003. 
SECTI, Secretaria de Ciência, Tecnologia e Inovação de Pernambuco, ESTRATÉGIA de Ciência, Tecnologia e Inovação para Pernambuco 2017-2022. Disponível em:<http://secti.pe.gov.br>, março de 2017

SCHUMPETER, J. A. Teoria do desenvolvimento econômico: uma investigação sobre lucros, capital, crédito, juro e o ciclo econômico (1 ed., 1934). Tradução de Maria Sílvia Possas. Coleção Os Economistas. São Paulo: Nova Cultural, 1997.

SICSÚ, A. B., Políticas Públicas para Inovação no Brasil: Mudanças necessárias. Estudos Universitários (UFPE), v. 31, p. 41-56, 2012.

ZOROVITCH, Marcelo R. e S., As Relações Empresas-Governo na Formação das Cadeias Globais de Valor no Setor Automotivo, In: 3ํㅗㄹ Seminário de Relações Internacionais Graduação e Pós Graduação, Florianópolis. Economia Política Internacional, 2016.

\section{Sites Visitados:}

http://mundofca.com/centro-de-pesquisa-desenvolvimento-giovanni-agnelli/ http://www.fcapress.com.br/pt/fca/verRelease/1719.do https://garagem360.com.br/fca-inaugura-centro-de-pesquisa-e-desenvolvimento-nobrasil/ 